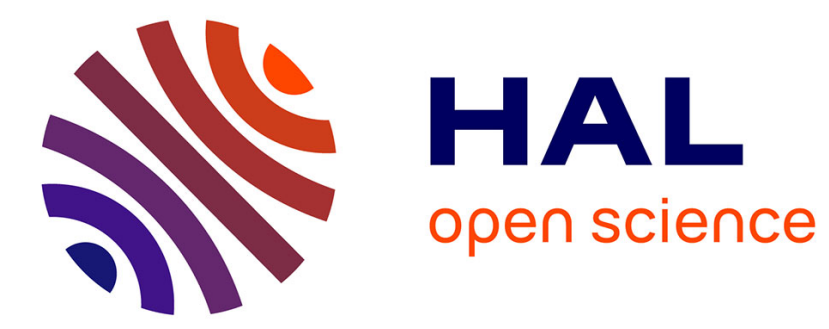

\title{
The ground state spin of 180Ta is not $8+$
}

E. Warde, R. Seltz, G. Costa, D. Magnac, C. Gerardin

\section{To cite this version:}

E. Warde, R. Seltz, G. Costa, D. Magnac, C. Gerardin. The ground state spin of $180 \mathrm{Ta}$ is not $8+$. Journal de Physique Lettres, 1979, 40 (1), pp.1-3. 10.1051/jphyslet:019790040010100 . jpa-00231555

\section{HAL Id: jpa-00231555 https://hal.science/jpa-00231555}

Submitted on 1 Jan 1979

HAL is a multi-disciplinary open access archive for the deposit and dissemination of scientific research documents, whether they are published or not. The documents may come from teaching and research institutions in France or abroad, or from public or private research centers.
L'archive ouverte pluridisciplinaire HAL, est destinée au dépôt et à la diffusion de documents scientifiques de niveau recherche, publiés ou non, émanant des établissements d'enseignement et de recherche français ou étrangers, des laboratoires publics ou privés. 


\title{
LE JOURNAL DE PHYSIQUE-LETTRES
}

Classification

Physics Abstracts

$21.10 \mathrm{H}-21.60$

\section{The ground state spin of ${ }^{180} \mathrm{Ta}$ is not $8^{+}$}

\author{
E. Warde (*), R. Seltz, G. Costa, D. Magnac and C. Gerardin \\ C.R.N. and U.L.P., Basses Energies, 67037 Strasbourg, France
}

(Reçu le 30 octobre 1978, accepté le 13 novembre 1978)

\begin{abstract}
Résumé. - Des membres des bandes rotationnelles $\left(1^{+}, 1\right)$ et $\left(8^{+}, 8\right)$ ont été identifiés dans la région de faible excitation de ${ }^{180} \mathrm{Ta}$ par une comparaison des sections efficaces de transfert $(p, d)$ avec des calculs en DWBA, utilisant des fonctions d'onde de Nilsson.
\end{abstract}

Abstract. - Experimental (p, d) cross-sections are compared with calculations using Nilsson wave functions and the DWBA in order to locate the members of the low lying $\left(1^{+}, 1\right)$ and $\left(8^{+}, 8\right)$ rotational bands in ${ }^{180} \mathrm{Ta}$.

Until recently [1] only two levels have been observed in ${ }^{180} \mathrm{Ta}$, both isomers. The long-lived isomer, considered as the ground state, has $T_{1 / 2}>10^{13}$ y [2], [3]. The other level with $T_{1 / 2}=8.15 \mathrm{~h}$. has been previously located at $212 \mathrm{keV}$ [4], [5] and recently at $32 \mathrm{keV} \mathrm{[6].}$ The log $f t$ values for the decay of the latter level to the $0^{+}$and $2^{+}$first excited states of ${ }^{180} \mathrm{~W}$ and ${ }^{180} \mathrm{Hf}$, are consistent with allowed or possibly first forbidden transitions. Asaro et al. [7] suggested values of $I^{\pi}$, $K=1^{-}, 0$ and $I^{\pi}, K=8^{+}, 8$ or $9^{-}, 9$ respectively for the short-lived (SLI) and long-lived (LLI) isomers.

Experimental observations by Gallagher et al. [8] on the SLI decay exclude the $\left(1^{-}, 0\right)$ assignment which arises from the coupling of $9 / 2^{-}[514 \uparrow]_{p}$ with $9 / 2^{+}[624 \uparrow]_{\mathrm{n}}$ with antiparallel spins $(\Sigma=0)$. The same experiment is consistent with $\left(1^{+}, 1\right)$ explained as due to the coupling of $7 / 2^{+}[404 \downarrow]_{p}$ with the $9 / 2^{+}[624 \uparrow]_{n}$ with parallel intrinsic spins $(\Sigma=1)$. The two configurations mentioned above give rise also to states with $\left(9^{-}, 9\right) \Sigma=1$ and $\left(8^{+}, 8\right) \Sigma=0$. Both of these spins have been proposed for the LLI and the experimental study has not solved this ambiguity. The intrinsic proton state $9 / 2^{-}[514 \uparrow]_{\mathrm{p}}$ of the $\left(9^{-}, 9\right)$ configuration in ${ }^{180} \mathrm{Ta}$ appears in ${ }^{181} \mathrm{Ta}$ at $6 \mathrm{keV}$ above the $7 / 2^{+}[404 \downarrow]_{\mathrm{p}}$ ground state which corresponds to the $\left(8^{+}, 8\right)$ configuration. Due to this very small energy difference the $\left(9^{-}, 9\right)$ as well as the $\left(8^{+}, 8\right)$ states could be the LLI. However in all other known odd-odd tantalum nuclei the ground state proton configuration is due to the coupling with parallel intrinsic spins of the $7 / 2^{+}[404 \downarrow]_{p}$ with a neutron state.

$\left(^{*}\right)$ On leave from University of Lattakia (Syria).
If one adopts $\left(1^{+}, 1\right)$ for the SLI, the identification of the $\left(8^{+}, 8\right)$ member of this configuration with a lower lying state would violate the Gallagher-Moszkowski empirical rule (G-M rule) [9]. This rule states that the member of the doublet corresponding to parallel intrinsic spins of the unpaired nucleons has the lowest excitation. As far as is known, such a violation has been observed once in ${ }^{166} \mathrm{Ho}$ where the ground state is $\left(0^{-}, 0\right)\left(\Sigma_{\mathrm{p}}+\Sigma_{\mathrm{n}}=\Sigma=0\right)$ but only $5 \mathrm{keV}$ below the $\left(7^{-}, 7\right)$ member $(\Sigma=1)$. It must be pointed out that in this case the long-lived isomer $\left(T_{1 / 2}>1.2 \times 10^{3} \mathrm{y}\right)$ is not the ground state which has $T_{1 / 2}=27 \mathrm{~h}$. [10].

The doublet $K_{<}=1^{+}$and $K_{>}=8^{+}$from the configuration $\left\{7 / 2^{+}[404 \downarrow]_{p}, 9 / 2^{+}[624 \uparrow]_{n}\right\}$ has been observed in ${ }^{176} \mathrm{Lu}$ and the $\left(8^{+}, 8\right)$ member lies $206 \mathrm{keV}$ above the $\left(1^{+}, 1\right)$ again in agreement with the G-M rule [1].

The aim of this letter is to propose, with the help of new experimental data, an alternative to the low lying level scheme of ${ }^{180} \mathrm{Ta}$ and to try to explain some of the contradictions outlined above.

The ${ }^{180} \mathrm{Ta}$ nucleus has been investigated by the ${ }^{181} \mathrm{Ta}(\mathrm{p}, \mathrm{d}){ }^{180} \mathrm{Ta}$ reaction at $E_{\mathrm{p}}=19 \mathrm{MeV}$ using a magnetic spectrograph. The experimental procedure is described elsewhere [1].

Assuming a direct transfer mechanism, the observed excited states in the low energy region result from the coupling of the transferred neutron with the unpaired proton of the target ground state e.g. $7 / 2^{+}[404 \downarrow]_{p}$. The lowest neutron state is $9 / 2^{+}[624 \uparrow]_{n}$, ground state configuration of ${ }^{177} \mathrm{Yb},{ }^{179} \mathrm{Hf}$ and ${ }^{181} \mathrm{~W}$, all isotones of ${ }^{180} \mathrm{Ta}$. It is this configuration which produces the Gallagher-Moszkowski doublet with $K_{<}^{\pi}=1^{+}$and 
$K_{>}^{\pi}=8^{+}$. Among other possible neutron states below $900 \mathrm{keV}$ excitation the $9 / 2^{+}$[624 $\left.\uparrow\right]$ is the only one with even parity [12]. The expected transfers to the members of the two bands built with this neutron state are $l=4, j=9 / 2\left(C_{j l}^{\Omega}=0.126\right)$ and $l=6$, $j=13 / 2\left(C_{j l}^{\Omega}=0.98\right)$. We exclude the $l=6, j=11 / 2$ transfer because the corresponding $C_{j l}^{\Omega}$ is negligible.

For the two first members of the $1^{+}$band, the only allowed transfer is $l=4$ with a relatively small intensity. The $8^{+}$band, in contrast is excited by $l=4$ and strongly so by $l=6$. Referring to the energy of the observed lowest level, taken to zero, we see that the angular distributions of the levels at 0 and $41 \mathrm{keV}$ are well fitted by a pure $l=4$ transfer (Fig. 1a).
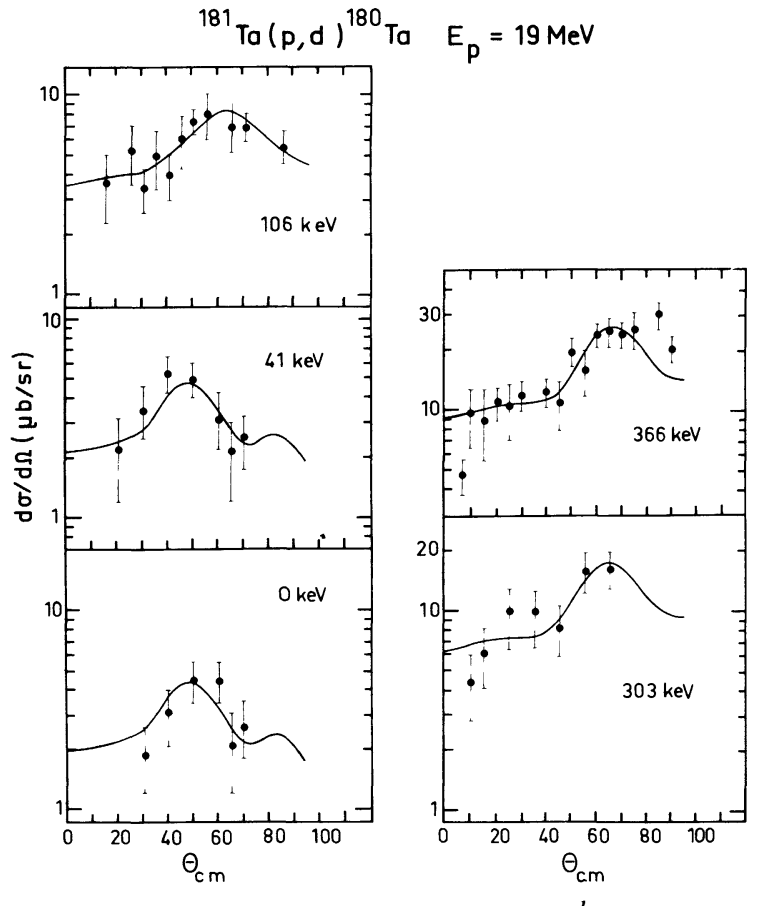

The two first levels are observed with a large experimental error, but the theoretical absolute crosssections represent $60 \%$ of the observed cross-sections. In contrast the $\left(8^{+}, 8\right)$ absolute theoretical crosssection is more than two times too large to fit either of these levels. Furthermore the $\left(3^{+}, 1\right)$ member of the $1^{+}$band is easily identified with the level at $106 \mathrm{keV}$ by taking an inertia parameter $\hbar^{2} / 2 J=10.5 \mathrm{keV}$ [1]. Both the angular distribution and absolute crosssections are fitted (Table I; Fig. 1a).

In a previous paper [1], we have shown that the $\left(4^{+}, 1\right)$ member of this band is a part of the experimental multiplet at $173 \mathrm{keV}$ including the $\left(8^{+}, 8\right)$ state. An additional proof of the location of this member of the G-M doublet is given by the state observed at $366 \mathrm{keV}$ which is identified as the $\left(9^{+}, 8\right)$. Its angular distribution is $l=6$ as expected (see Fig. $1 b)$. This is the only $l=6$ angular distribution in this energy region and a good agreement between theoretical and experimental cross-sections is found (Table I). This identification leads to the location of the $\left(8^{+}, 8\right)$ band head at $177 \mathrm{keV}$ in good agreement with a previous identification based essentially on cross-section considerations [1].

The $\left(5^{+}, 1\right)$ state is expected at $294 \mathrm{keV}$, with an $l=6$ angular distribution. Experimentally one observes a level at $303 \mathrm{keV}$ showing an angular distribution dominated by $l=6$ (see Fig. $1 b$ ). The major part of the measured cross-section comes from the $\left(5^{+}, 1\right)$ state.

Hence the members of the $\left(1^{+}, 1\right)$ band have been identified with a good degree of confidence up to $\left(5^{+}, 1\right)$. The $\left(8^{+}, 8\right)$ member of the G-M doublet is shown to be above the $\left(1^{+}, 1\right)$ level. In addition to arguments quoted in the introduction it has been shown that if the lowest level observed in our experiment was assigned $\left(8^{+}, 8\right)$ it would be impossible to explain the energy and transfer cross-sections of other low lying observed levels. Finally, the proposed level scheme leads to a G-M term of the $V_{\text {np }}$ residual interaction of $A=-104 \mathrm{keV}$ in very good agreement

Fig. 1. - Angular distributions of states in ${ }^{180} \mathrm{Ta}$ excited by the ${ }^{181} \mathrm{Ta}(\mathrm{p}, \mathrm{d}){ }^{180} \mathrm{Ta}$ reaction at $E_{\mathrm{p}}=19 \mathrm{MeV}$. Solid lines are theoretical calculations using Nilsson wave functions and DWBA : a) Members of the $\left(1^{+}, 1\right)$ band ; $\left.b\right)$ Members of the $\left(8^{+}, 8\right)$ band.

Table I. - Experimental and theoretical cross-sections for members of the $\left(1^{+}, 1\right)$ and $\left(8^{+}, 8\right)$ bands in ${ }^{180}$ Ta excited in the ${ }^{180} \mathrm{Ta}(\mathrm{p}, \mathrm{d}){ }^{181} \mathrm{Ta}$ reaction.

\begin{tabular}{lcccccr} 
& \multicolumn{2}{c}{ Energy (keV) } & \multicolumn{2}{c}{ Cross-section $(\mu \mathrm{b} / \mathrm{sr})$} & \multicolumn{2}{c}{ Theory } \\
\multicolumn{1}{c}{$I^{\pi}, K$} & \multicolumn{1}{c}{ Exp. } & Theory $\left({ }^{b}\right)$ & $\sigma\left(45^{\circ}\right)$ & $\sigma\left(65^{\circ}\right)$ & $\sigma\left(45^{\circ}\right)$ & $\sigma\left(65^{\circ}\right)$ \\
- & - & - & - & - & - & - \\
$1^{+}, 1$ & 0 & 0 & $4.5 \pm 1.0\left(^{(c)}\right.$ & $2.1 \pm 0.9$ & $2.50\left({ }^{c}\right)$ & 1.48 \\
$2^{+}, 1$ & 41 & 42 & $5.0 \pm 1.0\left(^{(}\right)$ & $2.1 \pm 0.9$ & $2.64\left(^{c}\right)$ & 1.57 \\
$3^{+}, 1$ & 106 & 105 & $6.3 \pm 1.7$ & $7.0 \pm 2.0$ & 3.86 & 5.26 \\
$4^{+}, 1\left(^{a}\right)$ & 173 & 189 & $34.5 \pm 5.5$ & $43.5 \pm 6.4$ & 5.93 & 10.68 \\
$5^{+}, 1$ & 302 & 294 & $8.2 \pm 2.2$ & $16.0 \pm 3.0$ & 6.10 & 12.06 \\
$8^{+}, 8\left(^{a}\right)$ & 173 & 177 & $34.5 \pm 5.5$ & $43.5 \pm 6.4$ & 10.07 & 9.87 \\
$9^{+}, 8$ & 366 & 366 & $11.0 \pm 4.0$ & $24.5 \pm 5.0$ & 8.76 & 18.20
\end{tabular}

$\left({ }^{a}\right)$ Unresolved in experiment (see Ref. [1]).

(b) Given by $E\left(I^{\pi}, K\right)=E\left(K^{\pi}, K\right)+\hbar^{2} / 2+\left[I(I+1)-K^{2}\right]$ with $\hbar^{2} / 2 t=10.5 \mathrm{keV}$.

(c) Cross-section at $\theta_{\mathrm{lab}}=50^{\circ}$. 
with calculations of Boisson et al. for this configuration [13].

There are many uncertainties in previous works on ${ }^{180} \mathrm{Ta}$. It was first admitted that the SLI is located above the LLI. But from more recent data [14] and from neutron binding energy systematics [15] it cannot be excluded that the lower excited state is the SLI. The facts which appear to be well established are that the SLI is a $\left(1^{+}, 1\right)$ state and the LLI a state with $K \geqslant 8$, although experimental results on the decay of the long-lived isomer are scarce [2], [3]. From the present work it is established that the $\left(1^{+}, 1\right)$ state with configuration $\left\{7 / 2^{+}[404 \downarrow]_{\mathrm{p}}, 9 / 2^{+}[624 \uparrow]_{\mathrm{n}}\right\}$ is excited at lower energy than the $\left(8^{+}, 8\right)$ which belongs to the same G-M doublet.

If the LLI is the $\left(8^{+}, 8\right)$ state then it must be an excited state at least at $180 \mathrm{keV}$.

The other state of high spin, the $\left(9^{-}, 9\right)$ of configuration $\left\{9 / 2^{-}[514 \uparrow]_{\mathrm{p}}, 9 / 2^{+}[624 \uparrow]_{\mathrm{n}}\right\}$ which cannot be excited in this neutron transfer reaction, could be the long-lived isomer and be above or below the $\left(1^{+}, 1\right)$. Furthermore we cannot completely exclude another configuration for the $\left(1^{+}, 1\right)$ that is $\left\{9 / 2^{-}[514 \uparrow]_{\mathrm{p}}, 7 / 2^{-}[514 \downarrow]_{\mathrm{n}}\right\}$ also unobservable in a pick-up from ${ }^{181} \mathrm{Ta}$. The $\beta^{-}$and E.C. decay properties measured experimentally [8] are compatible with such a configuration but the corresponding $1^{+}$state is expected above the $\left(1^{+}, 1\right)$ band head identified here.

From these results one concludes that if the longlived isomer is the lower excited state and if the shortlived isomer is the $\left(1^{+}, 1\right)$ identified here, then the $\left(9^{-}, 9\right)$ state is the only reasonable candidate for the long-lived isomer. Finally, concerning the ground state spin of ${ }^{180} \mathrm{Ta}$ only two assignments are possible, either $\left(1^{+}, 1\right)$ from $\left\{7 / 2^{+}[404 \downarrow]_{\mathfrak{p}}, 9 / 2^{+}[624 \uparrow]_{\mathrm{n}}\right\}$ or $\left(9^{-}, 9\right)$ from $\left\{9 / 2^{-}[514 \uparrow]_{\mathrm{p}}, 9 / 2^{+}[624 \uparrow]_{\mathrm{n}}\right\}$. In any case the spin $\left(8^{+}, 8\right)$ is excluded. The excitation of ${ }^{180} \mathrm{Ta}$ via a proton transfer reaction, $\left({ }^{3} \mathrm{He}, \mathrm{d}\right)$ or $(\alpha, \mathrm{t})$ would help to choose between $1^{+}$or $9^{-}$.

Acknowledgments. - We thank Dr. R. Piepenbring for his stimulating interest in this work and critical reading of the manuscript.

\section{References}

[1] Warde, E., Seltz, R., Costa, G., Magnac, D. and Gerardin, C., J. Physique Lett. 39 (1978) L-161 and to be published.

[2] Saкамото, K., Nucl. Phys. A 103 (1967) A134.

[3] Ardisson, G., Radiochem. Radioanal. Lett. 29 (1977) 7.

[4] Brown, H. N., Bendel, W. L., Shore, F. J. and Becker, R. A., Phys. Rev. 84 (1951) 292.

[5] Geller, K. N., Halpern, J. and Muirhead, E. G., Phys. Rev. 118 (1960) 1302.

[6] Wapstra, A. H. and Gove, N. B., quoted in Nucl. Data Sheets 15 (1975) 577.

[7] Asaro, F., Perlman, I., Rasmussen, J. O. and Thompson, S. G., Phys. Rev. 120 (1960) 934.

[8] Gallagher, C. J. Jr., Jorgensen, M. and Skilbreid, O., Nucl. Phys. 33 (1962) 285.
[9] Gallagher, C. J. and Moszkowski, S. A., Phys. Rev. 111 (1958) 1282.

[10] Nucl. Data Sheets 14 (1975) 514.

[11] Balodis, M. K., Tambergs, J. J., Alknis, K. J., Prokofjev, P. T., Vonach, W. G., Vonach, H. K., КосH, H. R., Gruber, U., Maier, B. P. K. and Schult, O. W. B., Nucl. Phys. A 194 (1972) 305.

[12] Bunker, M. E. and Reich, C. W., Rev. Mod. Phys. 43 (1971) 348.

[13] Boisson, J. P., Piepenbring, R. and Ogle, W., Phys. Rep. 26 (1976) 99.

[14] Lanier, R. G., Larsen, J. T., White, D. H. and Gregory, M. C., Bull. Am. Phys. Soc. 17 (1972) 899.

[15] Wapstra, A. H. and Bos, K., Atomic Data and Nucl. Data Tables 20 (1977) 16. 